\title{
DYNAMIC IDENTIFICATION OF THE SO-CALLED TEMPLE OF MINERVA MEDICA: COMPARISON OF DIFFERENT INSTRUMENTATIONS AND METHODS FOR MUTUAL VALIDATION OF THE RESULTS
}

\author{
C. BAGGIO ${ }^{1}$, V. SABBATINI ${ }^{*}$, S. SANTINI ${ }^{1}$, C. SEBASTIANI ${ }^{1}$ \\ V. FIORITI ${ }^{2}$, I. ROSELLI ${ }^{2}$, A. COLUCCI ${ }^{2}$, F. SAITTA ${ }^{2}$, S. FORLITI ${ }^{2}$ \\ ${ }^{1}$ Roma Tre University, Department of Architecture \\ Largo Giovanni Battista Marzi 10, 00153, Rome, Italy \\ Email: valerio.sabbatini@uniroma3.it (*corresponding author) \\ ${ }_{2}$ ENEA \\ Casaccia Research Center, \\ Via Anguillarese 301, Rome, Italy
}

Keywords: Historical Structure, Masonry, Operational Modal Analysis, Dynamic Identification, NonDestructive Inspection, Accelerometer vs Velocimeter

\begin{abstract}
Dynamic monitoring is a well-established technique used to gain information on the global health of constructions. In particular, ambient vibration tests have achieved important results in the dynamic characterization of modal parameters. Several techniques and instrumentations are currently available, however the accuracy of these results is often unquestioned. The mutual validation between different modal analysis techniques is an important procedure to assess the reliability of the results. In the present paper the ambient vibration tests performed on the so-called 'Temple of Minerva Medica' in Rome considering different techniques and instrumentations will be described and compared. While it is referred to as the Temple of Minerva Medica, the structure is actually a ruined decagonal nymphaeum in opus latericium that dates to the 4th century AD. Today, the construction is located between the main central train station (Roma Termini) and the local tram way. Ambient vibration data were acquired during different campaigns [1] to characterize the effects of the vibrations and the modal parameters of the structure. This work deals with the data collected on the 11th of July 2019 within the project "Tecnologie per il miglioramento della Sicurezza e la ricostruzione dei centri Storici in area sismica" coordinated by DTC Lazio (Distretto Tecnologico beni e attività culturali). The instrumentation comprised of several seismographs equipped with triaxial velocimeters and piezoelectric accelerometers. A variety of techniques were applied to process the acquired vibration data in order to extract the modal parameters of the studied structure including PolyMAX, FDD, EFDD, CC-SSI, HVSR and FRF. Comparison of the modal parameters obtained by each different technique was considered to provide indications on the reliability of the instruments.
\end{abstract}




\section{INTRODUCTION}

The accurate and reliable characterization of structures and materials provides crucial information in the restoration and conservation of historic constructions. In recent years, Structural Health Monitoring has had extraordinary success due to the sustainability of its techniques and the relevance of its results. Dynamic identification is a well-established technique; its results play a significant role in the prediction of the seismic response of the construction and they are commonly used as reference to update material properties and boundary conditions of complex numerical models [2]. However, the reliability of the results is subject to several uncertainties related to the acquisition and processing of data.

In the present paper through the case study of the so-called Temple of Minerva Medica located in Rome, different dynamic identification techniques and instruments are presented and compared in order to evaluate the accuracy and efficacy of the results.

\section{THE SO-CALLED TEMPLE OF MINERVA MEDICA IN ROME}

The construction, built in the early 4th century, was originally a nymphaeum in the Horti Liciniani. The name "Temple of Minerva Medica" dates back to the 16 th century and it originated as an incorrect interpretation by Pirro Ligorio following the discovery of a statue of "Minerva con dracone" in the surrounding area [3]. The main hall of the complex has a decagonal polylobate plan with a diameter of $25 \mathrm{~m}$ and two orders of arcades with an overall height of $32 \mathrm{~m}$, today reduced to $24 \mathrm{~m}$ after the partial collapse of the dome in 1828 [4].

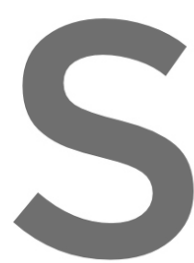

The structure was of tuff and Roman brick niches were closed and lower arcade of the south $2013[5]$
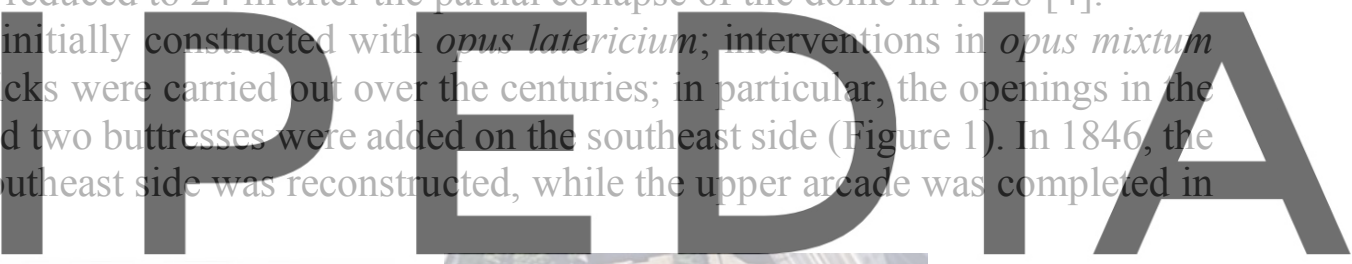

Register for free at https//www:scipedia.com to download the version without the watermark
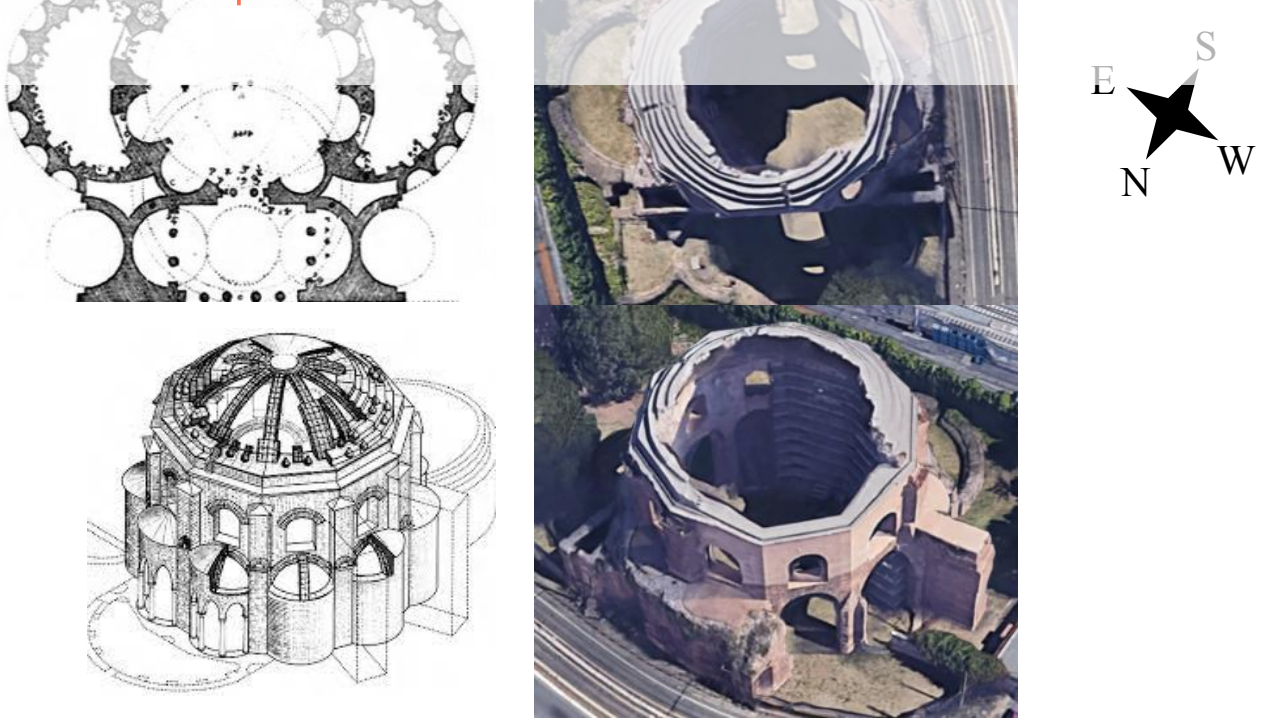

Figure 1: Possible original configuration [6] (left) and current condition (right) of the so-called Temple of Minerva Medica plan view (top) and perspective view from South (bottom) 


\section{THE EXPERIMENTAL CAMPAIGN}

While several experimental campaigns were carried out on the Temple of Minerva Medica [7] [8] [9], this work deals with the data collected on the 11 th of July 2019 within the project "Tecnologie per il miglioramento della Sicurezza e la ricostruzione dei centri Storici in area sismica" coordinated by DTC Lazio (Distretto Tecnologico beni e attività culturali).

Different sets of data were recorded considering two different types of instrumentations as shown in Figure 2.

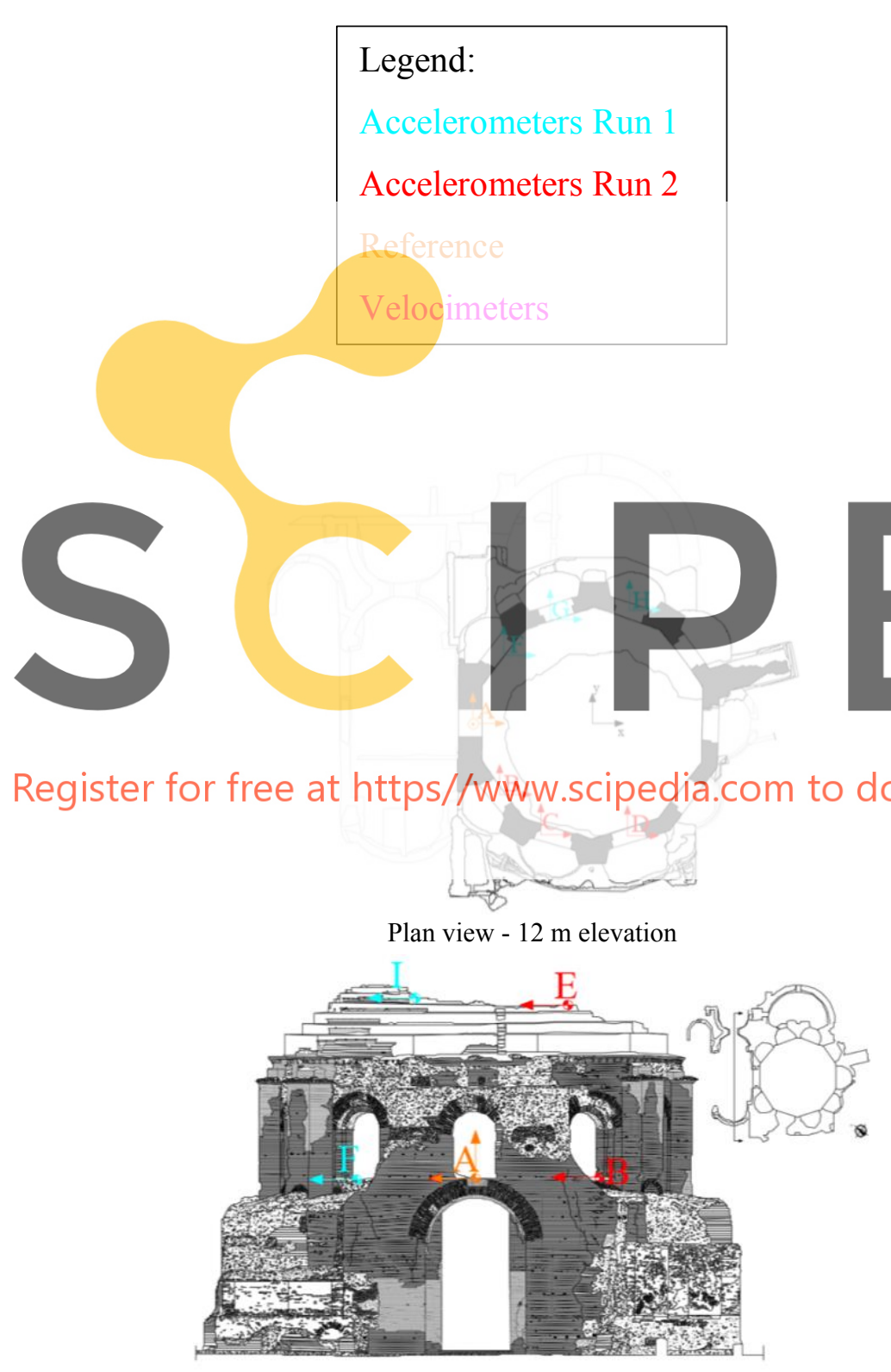

Elevation View - Northwest
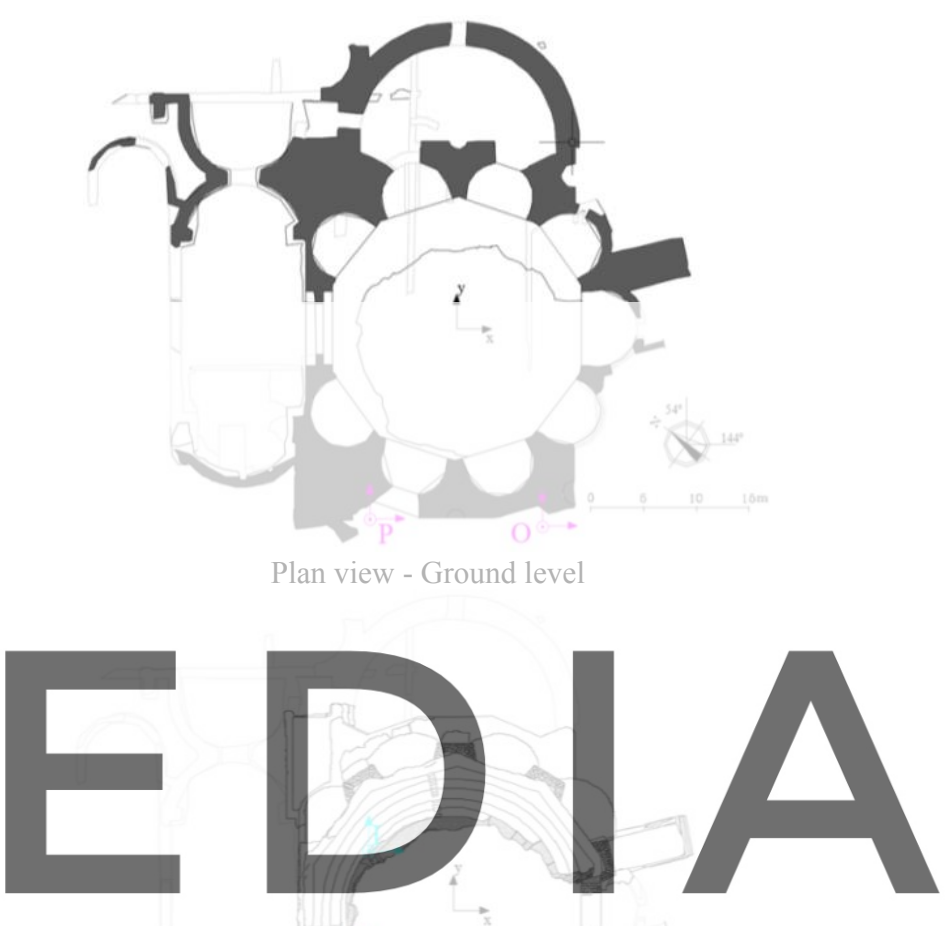


\subsection{Accelerometers}

Twelve ICP piezoelectric monoaxial accelerometers $(10 \mathrm{~V} / \mathrm{g}$ sensitivity, measure range \pm $0.5 \mathrm{~g}$, frequency range from 0.15 to $1000 \mathrm{~Hz}$ and $8 \mu \mathrm{g}$ rms resolution) were positioned on 5 different locations per run, cubical metal supports were used to orient the sensors according to a global reference system (Y-axis oriented $54^{\circ}$ clockwise from North). Two runs of accelerations were recorded, each one for a period of approximately 45 minutes, only one location was kept unvaried (A) as reference for the merging process. Data were acquired from approximately 10:00 AM to 4:00 PM (local time).

\subsection{Velocimeters}

Three seismometers were located in positions A, P and O. They are SL06 SARA Instruments digital recorders equipped with SS02 triaxial velocimeters. Each seismograph is independent and provided with battery for the energy supply and with a GPS antenna for synchronization to the U.T.C. time so that data from different instruments can be compared in the time domain. This instrumentation is generally used for measuring very low vibrations, such as seismic monitoring for the characterization of soil amplification and microzonation applications. It has sensitivity of $400 \mathrm{~V} / \mathrm{m} / \mathrm{s}$ and frequency range from 0.2 to $50 \mathrm{~Hz}$. In the present work sampling frequency was set at $200 \mathrm{~Hz}$. Data were acquired from 9:50 a.m. to 12:50 a.m. (local time). The seismographs were oriented with the same X, Y, Z directions as the accelerometers (see previous sub-section 3.1) in order to make data comparison easier.
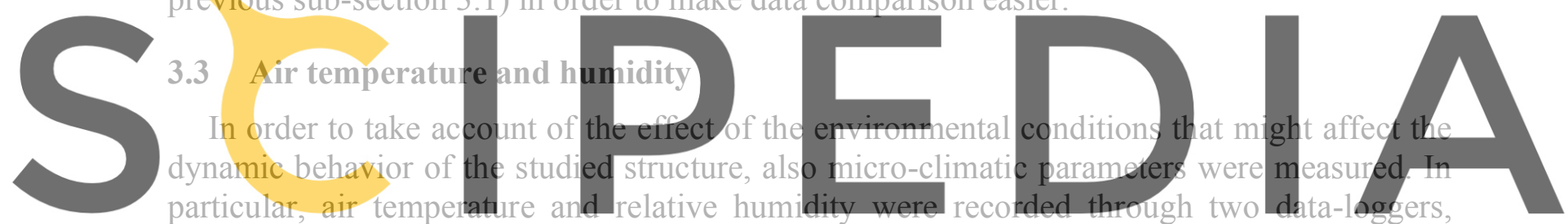
equipped with thermometer and humidity sensor, positioned at the Northeast and Southwest

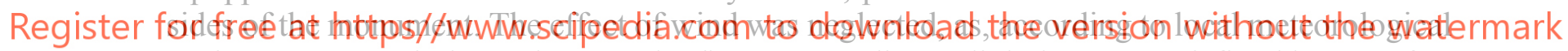
station, average wind speed was $10 \mathrm{~km} / \mathrm{h}$ corresponding to light breeze, as defined by Beaufort scale (or Beaufort number 2), during ambient vibration acquisition.

\section{PROCESSING AND RESULTS}

\subsection{Multi-run Operational Modal Analysis (accelerometers)}

The Temple of Minerva Medica is strongly affected by the vibrations caused by the local tram, the nearby train railway, and the vehicular traffic [9]. Moreover, the wind action, whose intensity was mostly constant during the acquisition, allows the assumption of zero Mean Gaussian white noise excitations, suitable for output only modal analysis [10].

The accelerometer measurements were recorded with a sampling frequency of $441 \mathrm{~Hz}$ and subsequently resampled to $60 \mathrm{~Hz}$ according to the significant frequency band of the building, the data was filtered with low cut frequency of $0.2 \mathrm{~Hz}$ and high cut of $30 \mathrm{~Hz}$ and then the Crossspectra were calculated with 1024 time lags and 1\% windowing.

Modal parameters were extracted through PolyMAX algorithm implemented in the software Simcenter Testlab [11]. PolyMAX is based on a common-denominator transfer function model, 
the Cross-spectra are processed in a complex polynomial rational function, whose grade represents the order of the model and the zeros of the denominator the poles that identify the modes of vibration of the system [12].

The extracted modal frequencies from the two sets of accelerations are reported in Table 1.

Table 1 Modal frequencies from the acceleration measurements

\begin{tabular}{cc|cc}
\hline \multicolumn{2}{c|}{ Run 1 } & \multicolumn{2}{c}{ Run 2 } \\
\hline Frequency [Hz] & Damping [\%] & Frequency [Hz] & Damping [\%] \\
\hline 2.064 & 0.93 & 2.054 & 0.36 \\
\hline 2.455 & 1.44 & - & - \\
\hline 2.579 & 1.31 & - & - \\
\hline 2.780 & 1.98 & 2.765 & 1.01 \\
\hline 3.598 & 1.49 & 3.601 & 0.89
\end{tabular}

The last step is to combine and scale the extracted modes to obtain the global modal parameters of the construction. The target modes were selected based on the optimum validation parameters (Modal Assurance Criterion, Modal Phase Collinearity, Mean Phase Deviation) [13]. The merging process is performed in accordance with MAC correspondence in band; the mapping between the

to the three common DC
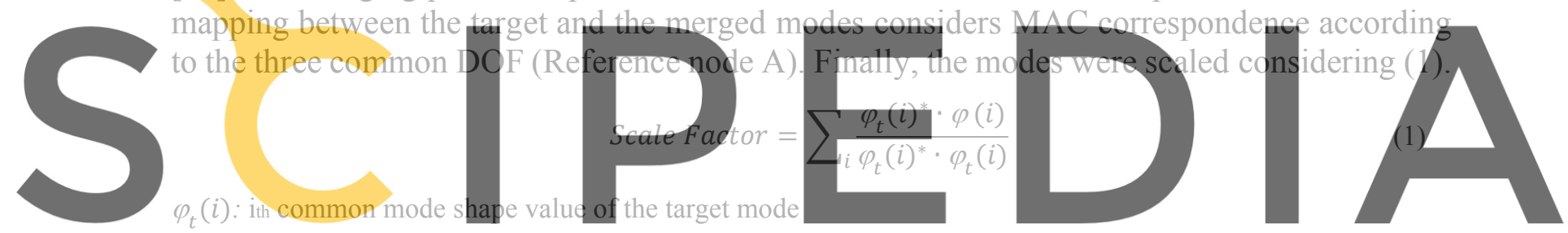

$\varphi(i)$ : ith common mode shape value of the mode to be merged

Register for free at https//WWW.scipedia.com to download the version without the watermark

The recorded data of Run 1 returned more accurate validation parameters, for this reason the

modal frequencies and damping of Runi were identified as final quantities, however the merging and scaling process of the modal shapes combined both the acquisitions with the following results.

The 1st mode expresses a global translational in the NW-SE direction.

The 2nd and 3rd modes identify the northwestern and the northeastern portion of the temple due to the only reliability of Run 1: the 2nd mode expresses a translational mode in the North direction coupled with a slight II order bending mode in the NW-SE direction, the 3rd mode expresses a main translational mode in the NE-SW direction with a small vertical component for the top of the construction.

The 4th mode expresses two coupled bending modes in the NW-SE and NE-SW direction basically a torsional mode.

The 5th mode is mostly translational in the NW-SE direction with II order bending component in the NE-SW direction for the northern portion of the temple.

The modal parameters and its main features are summarized in Figure 3. 
Reference System

and

Cardinal Directions

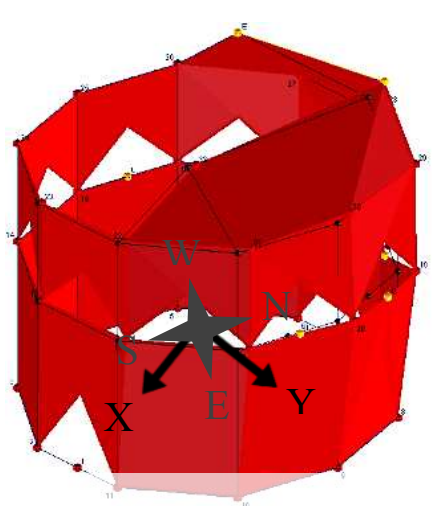

Mode 3

Translational NE-SW and Vertical

$f_{3}=2.57 \mathrm{~Hz}$

$\zeta_{3}=1.31 \%$
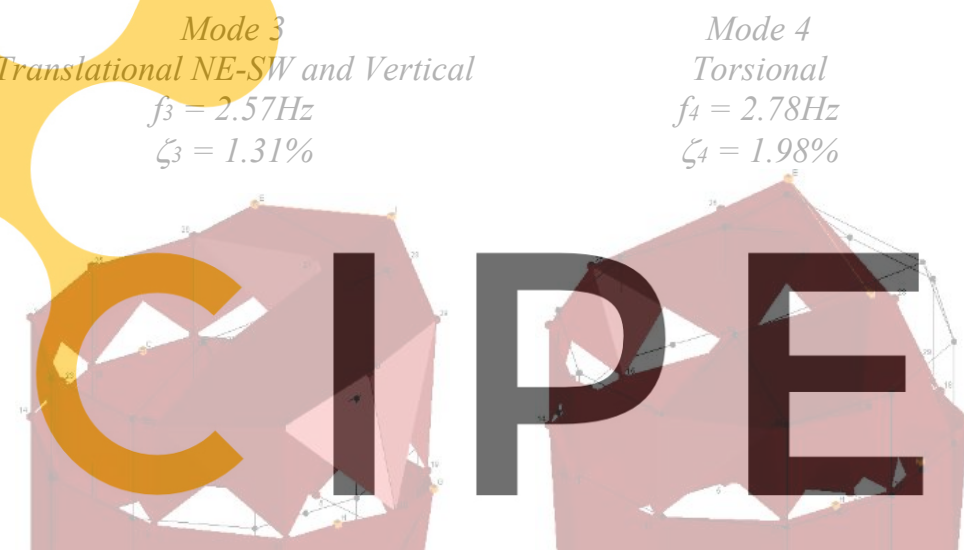

Mode 2

Translational NW-SE

$f_{l}=2.06 \mathrm{~Hz}$

$\zeta_{1}=0.93 \%$
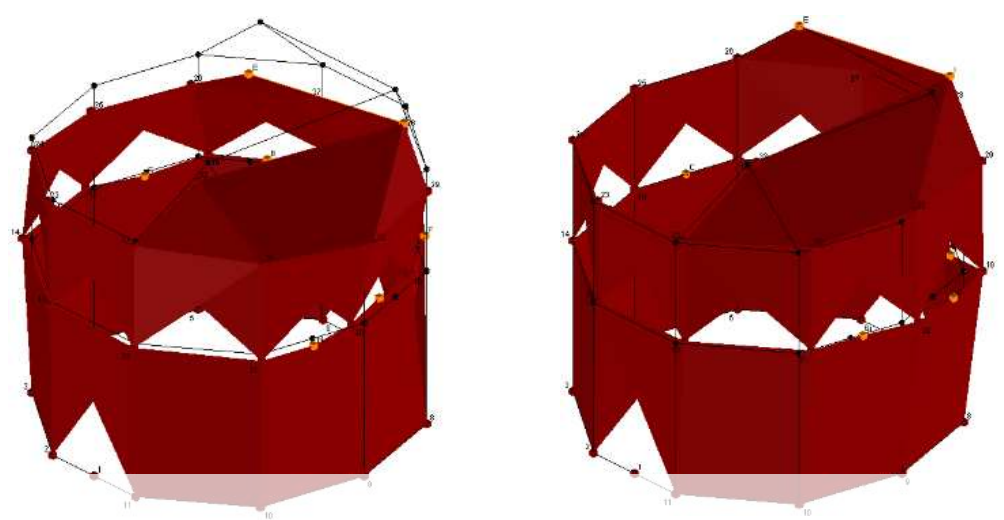

Mode 5

Translational NW-SE

$f_{5}=3.59 \mathrm{~Hz}$

$\zeta_{5}=1.49 \%$

Register for free at https//www.scipedia.com to download the version without the watermark

Figure 3: Extracted Modal Parameters

\subsection{Experimental and Operational Modal Analysis (velocimeters)}

Only velocimeters data acquired in late morning (after 12:00 a.m.) were considered in order to obtain results at environmental conditions comparable with the ones from accelerometers, which were acquired in the early afternoon. The measured air temperature at midday was $27-$ $28^{\circ} \mathrm{C}$, while the peak temperature in the afternoon was $29^{\circ} \mathrm{C}$.

The pre-processing procedure already applies low-pass filtering of data and conversion to velocity values. However, as the velocimeters mounted on the utilized seismographs provide affordable measurements for vibration frequencies higher than $0.2 \mathrm{~Hz}$, a high-pass band filter at $0.3 \mathrm{~Hz}$ was also applied.

The data were then processed with a variety of modal analysis methods. In particular, the Frequency Response Function (FRF) of position A (output signal on the elevated structure) with respect to positions $\mathrm{P}$ and $\mathrm{O}$ (input signal at ground level) was obtained (Figure 7). FRF 
was computed through an algorithm based on the $\mathrm{H}_{1}$ transmissibility function, which considers the cross-correlation of input and output signals at the numerator [14].

The triaxial signals of position A were processed to provide also the Horizontal-to-Vertical Spectral Ratio (HVSR) [15]. This was obtained by computing the ratio between the Power Spectral Density (PSD) of the horizontal components of the signals with respect to the vertical component (Figure 7).

Several output-only (OMA) techniques were applied. In particular, the Frequency Domain Decomposition (FDD), Enhanced Frequency Domain Decomposition (EFDD) and Crystal Clear Stochastic Subspace Identification (CC-SSI). As OMA methods assume that data provide white-noise low-intensity signals coming from random ambient vibration, the recordings were pre-treated in order to exclude the signal during tram passages, which induced strong vibration and might not be assumed as white-noise. Some examples of OMA analyses are shown in Figure 8.

The above analyses focused on detecting the first 5 modes of the monument.
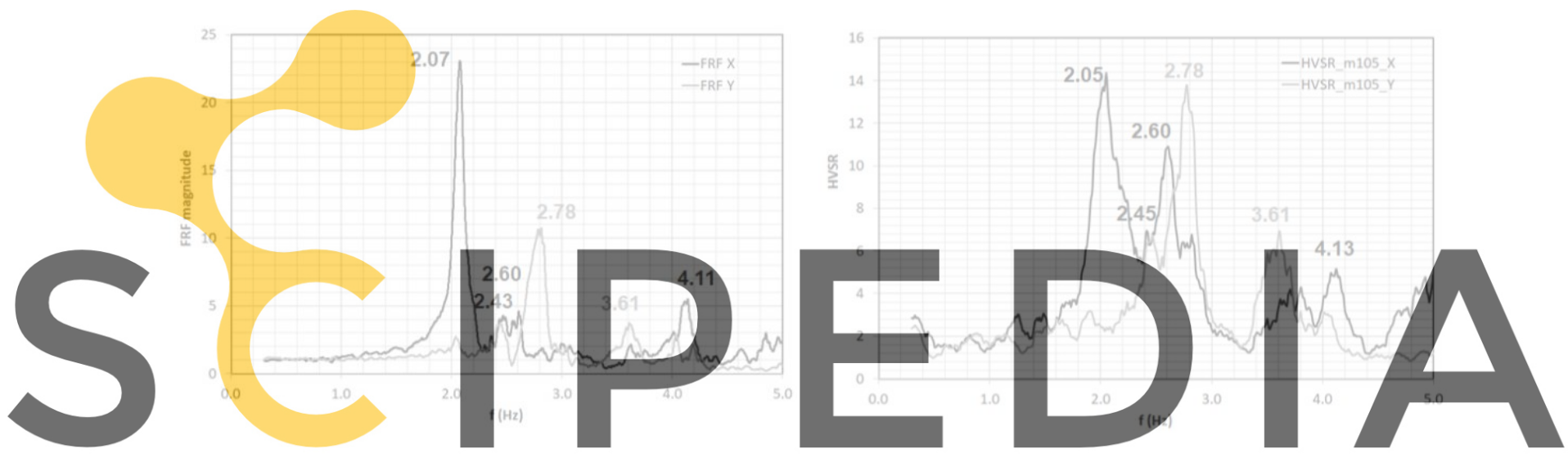

Figure 7: Identification of the modal frequencies by detecting the peaks in the FRF (left) and HVSR functions Register for free at https//wwW.Scipedia.com to download the version without the watermark

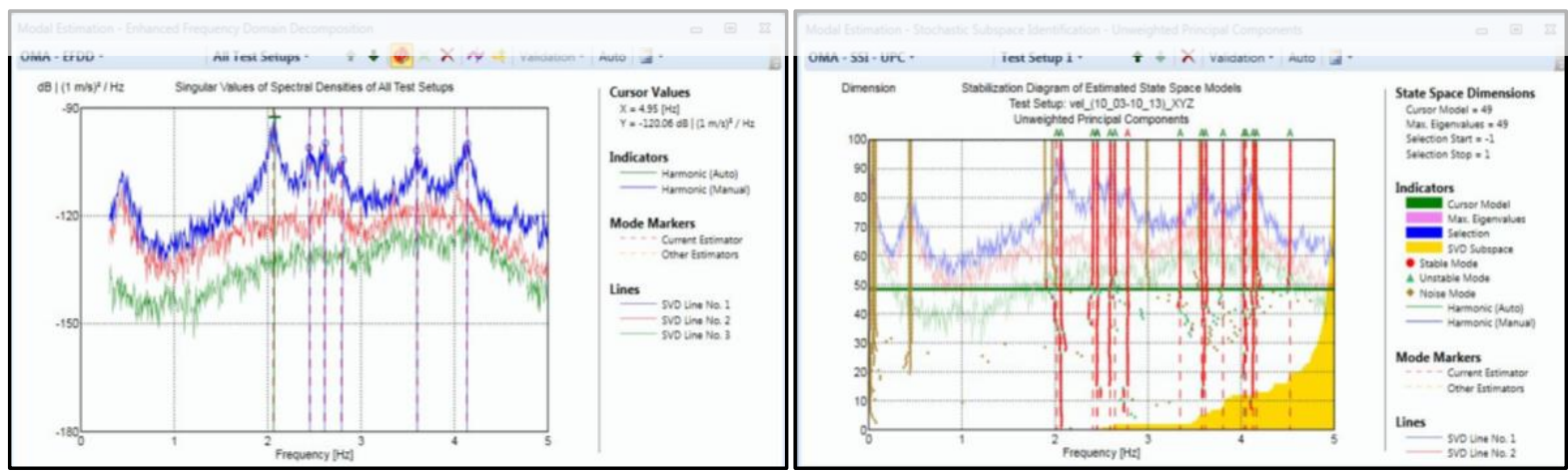

Figure 8: Identification of the modal frequencies by EFDD (left) and CC-SSI (right) techniques. 


\section{DISCUSSION}

\subsection{Finite element model}

An additional comparison of the experimental results was accounted by considering a finite element model (FEM) using the commercial software Midas Gen [16].

A fixed based model with a total number of 72980 solid elements and 19457 nodes have been adopted; the material has been modeled as homogeneous and isotropic with the following parameters: unit weight of $18 \mathrm{kN} / \mathrm{m}_{3}$, Poisson ratio of 0.2 and $744 \mathrm{MPa}$ of Young modulus.

The presented model was obtained by updating the initial value of the masonry (starting from the reference values of the Italian Code [17]), in order to achieve a sufficient match with the experimental frequencies. The results in terms of frequency and vibration modes are reported in Figure 4.
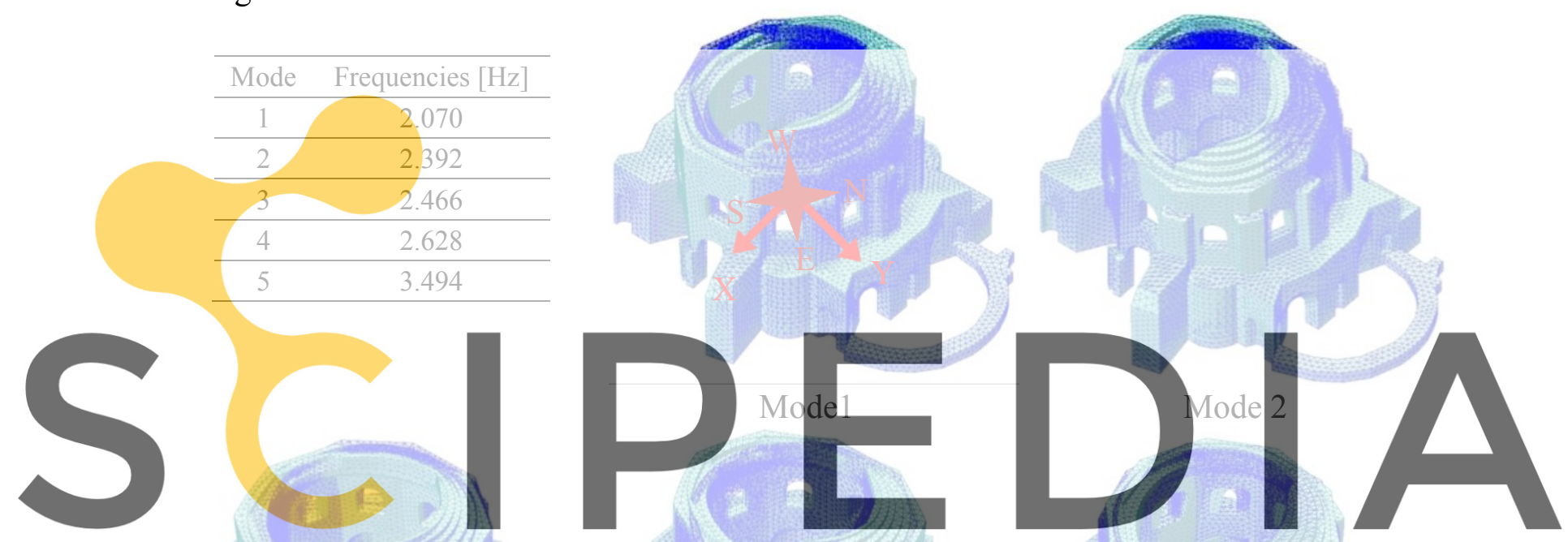

Register for free at https//www.scipedia.com to download the version without the watermark

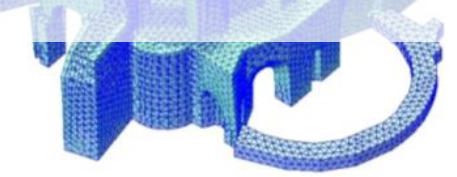

Mode 3

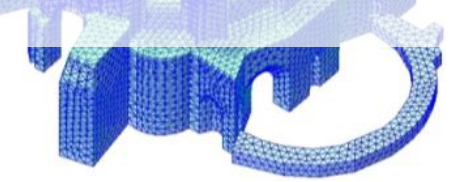

Mode 4

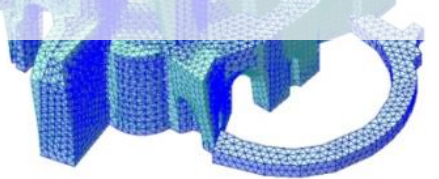

Mode 5

Figure 4 Numerical Vibration Modes

\subsection{Comparison}

The results from both the instrumentations and the different processing methods show an accurate correspondence of the modal frequencies with extremely small coefficient of variation and stable deviation standard between 0.009 and $0.012 \mathrm{~Hz}$ as reported in Table 2 . 
Table 2 Modal Frequencies comparison

\begin{tabular}{|c|c|c|c|c|c|c|c|c|c|c|}
\hline \multirow{3}{*}{ Mode } & \multicolumn{9}{|c|}{ Experimental } & \multirow{3}{*}{$\begin{array}{l}\text { Numerical } \\
\text { Frequency } \\
\text { MidasGen }\end{array}$} \\
\hline & \multicolumn{6}{|c|}{ Frequency $[\mathrm{Hz}]$} & \multicolumn{3}{|c|}{ Statistics } & \\
\hline & PolyMAX & FDD & EFDD & CC-SSI & HVSR & FRF & $\begin{array}{c}\text { Average } \\
{[\mathrm{Hz}]}\end{array}$ & $\begin{array}{l}\text { Standard } \\
\text { Dev. [Hz] }\end{array}$ & $\begin{array}{c}\text { Coefficient } \\
\text { Variation }\end{array}$ & \\
\hline 1 & 2.064 & 2.080 & 2.060 & 2.060 & 2.050 & 2.070 & 2.064 & 0.010 & $0.494 \%$ & 2.070 \\
\hline 2 & 2.455 & 2.440 & 2.450 & 2.450 & 2.450 & 2.430 & 2.446 & 0.009 & $0.375 \%$ & 2.392 \\
\hline 3 & 2.579 & 2.610 & 2.610 & 2.590 & 2.600 & 2.600 & 2.598 & 0.012 & $0.462 \%$ & 2.466 \\
\hline 4 & 2.780 & 2.810 & 2.790 & 2.780 & 2.780 & 2.780 & 2.787 & 0.012 & $0.435 \%$ & 2.628 \\
\hline 5 & 3.598 & 3.590 & 3.600 & 3.580 & 3.610 & 3.610 & 3.598 & 0.012 & $0.324 \%$ & 3.494 \\
\hline
\end{tabular}

By considering the average experimental frequencies as reference, the EFDD method return the most accurate results with an average frequency error of $0.20 \%$, followed by PolyMAX $(0.27 \%)$, CC-SSI $(0.28 \%)$, HVSR $(0.30 \%)$, FRF $(0.32 \%)$ and FDD $(0.51 \%)$. However, if the errors of mode 2 and 3 are excluded from the calculation, the average error of PolyMAX lows to $0.08 \%$ followed by EFDD with $0.12 \%$; this analysis confirms the small discrepancy of 2 nd and 3rd mode of vibrations identified by PolyMAX, this could be related to the difficulties in the validation of these frequencies in Run 2. In terms of frequency, the numerical model returned a sufficient correspondence with the experimental values, as a consequence, it can be performed a qualitativ displacements.

A rigorous comparison instrumentations was not possible since the
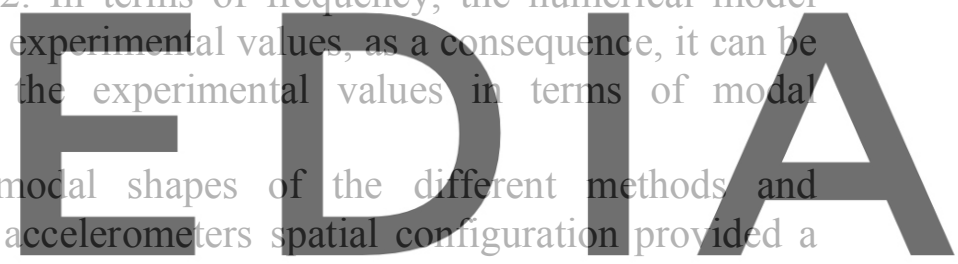
much more accurate description of the overall modal displacements; however, the normalized

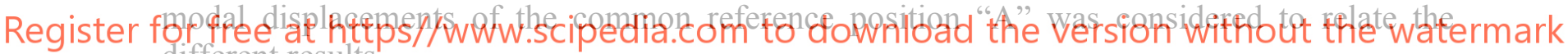
different results.

A simple statistical analysis was performed to compare the modal displacements resulted from the different processing of the velocimeter acquisition (Table 3). The velocimeter modal displacements returned more dispersed values than its frequency results as expressed by the coefficients of variation in Table 4; its average was considered enough representative to compare the displacements with the accelerometer and FEM values.

Table 3 Different processing of velocimeter modal displacements

\begin{tabular}{c|cccccccccc}
\cline { 2 - 11 } & \multicolumn{2}{|c}{ FDD } & \multicolumn{2}{c}{ EFDD } & \multicolumn{2}{c}{ CC-SSI } & \multicolumn{2}{c}{ HVSR } & \multicolumn{2}{c}{ FRF } \\
\hline Modes & $\mathrm{X}$ & $\mathrm{Y}$ & $\mathrm{X}$ & $\mathrm{Y}$ & $\mathrm{X}$ & $\mathrm{Y}$ & $\mathrm{X}$ & $\mathrm{Y}$ & $\mathrm{X}$ & $\mathrm{Y}$ \\
\hline 1 & $84 \%$ & $16 \%$ & $82 \%$ & $18 \%$ & $90 \%$ & $10 \%$ & $86 \%$ & $14 \%$ & $90 \%$ & $10 \%$ \\
\hline 2 & $46 \%$ & $-54 \%$ & $49 \%$ & $-51 \%$ & $46 \%$ & $-54 \%$ & $52 \%$ & $-48 \%$ & $53 \%$ & $-47 \%$ \\
\hline 3 & $53 \%$ & $47 \%$ & $51 \%$ & $49 \%$ & $41 \%$ & $59 \%$ & $62 \%$ & $38 \%$ & $68 \%$ & $32 \%$ \\
\hline 4 & $24 \%$ & $76 \%$ & $33 \%$ & $67 \%$ & $25 \%$ & $75 \%$ & $31 \%$ & $69 \%$ & $16 \%$ & $84 \%$ \\
\hline 5 & $-27 \%$ & $73 \%$ & $-27 \%$ & $73 \%$ & $-32 \%$ & $68 \%$ & $-35 \%$ & $65 \%$ & $-40 \%$ & $60 \%$ \\
\hline
\end{tabular}


Table 4 Different instruments modal displacements

\begin{tabular}{c|cc|cc|cccccc}
\cline { 2 - 10 } & \multicolumn{2}{c|}{ FEM } & \multicolumn{2}{c|}{ Accelerometer } & \multicolumn{5}{c}{ Velocimeter } \\
\cline { 2 - 11 } & \multicolumn{2}{c|}{ MidasGen } & \multicolumn{2}{c|}{ PolyMAX } & \multicolumn{2}{c}{ Average } & Standard Deviation & Coefficient Variation \\
\hline \multirow{2}{*}{ Modes } & $\mathrm{X}$ & $\mathrm{Y}$ & $\mathrm{X}$ & $\mathrm{Y}$ & $\mathrm{X}$ & $\mathrm{Y}$ & $\mathrm{X}$ & $\mathrm{Y}$ & $\mathrm{X}$ & $\mathrm{Y}$ \\
\hline 1 & $97.6 \%$ & $-2.4 \%$ & $96.2 \%$ & $-3.8 \%$ & $86.4 \%$ & $13.6 \%$ & $3.6 \%$ & $4.1 \%$ & $26.3 \%$ \\
\hline 2 & $-3.6 \%$ & $-96.4 \%$ & $-8.9 \%$ & $-91.1 \%$ & $49.2 \%$ & $-50.8 \%$ & $3.3 \%$ & $6.6 \%$ & $6.4 \%$ \\
\hline 3 & $-77.4 \%$ & $-22.6 \%$ & $-7.9 \%$ & $-92.1 \%$ & $55.0 \%$ & $45.0 \%$ & $10.4 \%$ & $18.9 \%$ & $23.1 \%$ \\
\hline 4 & $37.3 \%$ & $-62.7 \%$ & $50.6 \%$ & $49.4 \%$ & $25.8 \%$ & $74.2 \%$ & $6.7 \%$ & $25.9 \%$ & $9.0 \%$ \\
\hline 5 & $5.1 \%$ & $94.9 \%$ & $0.4 \%$ & $99.6 \%$ & $-32.2 \%$ & $67.8 \%$ & $5.5 \%$ & $17.2 \%$ & $8.2 \%$ \\
\hline
\end{tabular}

MAC [13] was calculated to evaluate the agreement of each mode (Table 5); the 1 st mode is perfectly represented by all the measurements as a MAC higher than $90 \%$ expresses a satisfactory match of the displacements. The rest of the modes present some similarities, the FEM and accelerometer results agree on the modal displacement of 2 nd and 5 th mode while the 3rd mode is well expressed by the modal displacement of the velocimeter and numerical model. All the results disagree on the 4 th mode behaviour. The coefficient of correlation was also evaluated to have a

the accelerometer retu
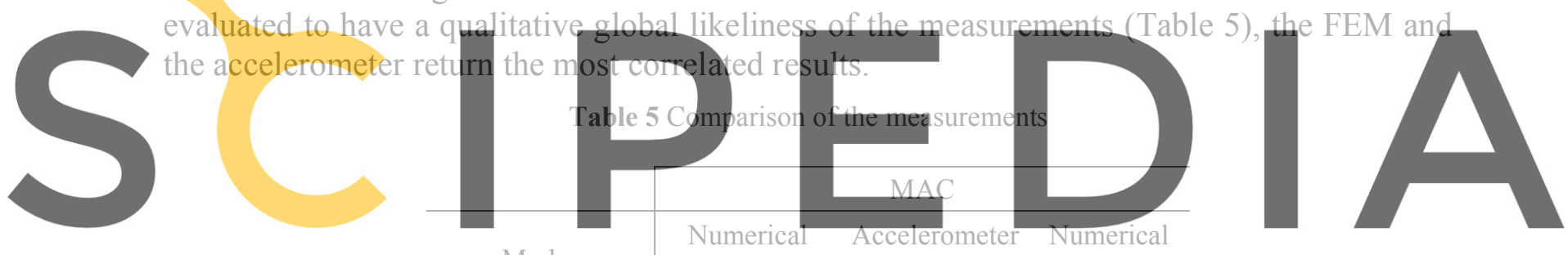

Register for free at https//Www.scipedia.com to download the velocimeter ion without the watermark

\begin{tabular}{c|ccc}
\hline 1 & $100.0 \%$ & $96.2 \%$ & $99.9 \%$ \\
\hline 2 & $99.6 \%$ & $41.9 \%$ & $0.1 \%$ \\
\hline 4 & $13.0 \%$ & $48.6 \%$ & $92.1 \%$ \\
\hline 5 & $5.5 \%$ & $80.0 \%$ & $26.1 \%$ \\
\hline Coeff. Correlation & $99.8 \%$ & $81.3 \%$ & $0.3 \%$ \\
\hline
\end{tabular}

\section{CONCLUSIONS}

Dynamic identification proved to be a reliable test for a historical masonry building located in an extremely disturbed urban area.

In general, seismometers are designed to be very sensitive for detecting weak signals of ground motion, as such, the instruments used in the present work have a frequency band from 0.2 to $50 \mathrm{~Hz}$ and sensitivity of $400 \mathrm{~V} / \mathrm{m} / \mathrm{s}$. However, the signal can saturate easily and the differentiation from velocity to acceleration introduce small numerical errors. On the other 
hand, piezoelectric accelerometers are generally used to record the response acceleration of structures to strong motion, however the instruments used have high sensitivity $(10 \mathrm{~V} / \mathrm{g})$, frequency band from 0.15 to $1000 \mathrm{~Hz}$ and range of $\pm 0.5 \mathrm{~g}$, which limits the possibility of overloads.

Despite the complex dynamic behavior of the so-called temple of Minerva Medica, both instrumentations returned extremely similar results in terms of frequency with remarkably contained coefficient of variation.

The extracted modal displacements yielded to sparse values, only the $1_{\text {st }}$ mode was accurately identified by all the instrumentations while the rest of the modes have partial agreements, in particular, the results from the accelerometers returned the highest correlation with the other values.

Dynamic monitoring of the so-called Temple of Minerva Medica identified irregular and partially coupled vibration modes, as a consequence, the modal displacements of the Northern and Western sides of the temple expressed wider amplitudes then the Eastern side where less sensors where located and the presence of the buttress partially retained the movements.

Regardless the complicated application, dynamic identification with different instrumentations and processing methods allowed a mutual validation of the results and highlighted the resilience of each approach.

The possibility to refer to multiple data and processing improves the reliability of the results and allows the confirmation or the repetition of the measurements.

\section{BIBLIOGRAPHY}

[1] I. Roselli, V. Fioriti, M. Mongelli, I. Bellagamba and G. De Canio, "Mutual Validation between different Modal Analysis Techniques for Dynamic Identification of the so-called Temple of Minerva Medica," in IOP Conf. Series: Materials Science and Engineering, Rome, 2018.

[2] C. Baggio, V. Sabbatini and S. Santini, "Model Updating of a Masonry Historical Church based on Operational Modal Analysis: the case study of San Filippo Neri in Macerata," in 7th International Conference on Computational Methods in Structural Dynamics and Earthquake Engineering, Crete, Greece, 24-26 June 2019.

[3] M. Barbera and M. Magnani Cianetti, Minerva Medica. Ricerche, scavi e restauri, Milano, Rome: Electra, 2019.

[4] M. Barbera, S. Di Pasquale and P. Palazzo, "Roma, studi e indagini sul cd. Tempio di Minerva Medica," The Journal of Fasti Online, 2007.

[5] M. Barbera, M. Magnani Cianetti and S. Barrano, Da Massenzio a Costantino: le indagini in corso nel c.d. Tempio di Minerva Medica, Bari: Edipuglia, 2014.

[6] RomanoImpero, "romanoimpero.com," 2015. [Online]. Available: https://www.romanoimpero.com/2015/02/tempio-di-minerva-medica.html.

[7] I. Roselli, A. Tatì, V. Fioriti, I. Bellagamba, M. Mongelli, R. Romano, G. De Canio, M. Barbera and M. Magnani Cianetti, "Integrated approach to structural diagnosis by non-destructive techniques: the case of the Temple of Minerva Medica," Acta IMEKO, vol. 7, no. 3, 2018. 
[8] V. Fioriti, I. Roselli, A. Tatì, R. Romano and G. De Canio, "Motion Magnification Analysis for structural monitoring of ancient constructions," Measurement, vol. 129, pp. 375-380, 2018.

[9] I. Roselli, V. Fioriti, I. Bellagamba, M. Mongelli, A. Tatì, M. Barbera, M. Magnani Cianetti and G. De Canio, "Impact of traffic vibration on the Temple of Minerva Medica, Rome: preliminary study within the CO.B.RA. Project," International Journal of Heritage Architecture, vol. 2, no. 1, pp. 102-114, 2018.

[10] C. Rainieri, Operational Modal Analysis for Seismic Protection of Structures, Napoli: University of Naples "Federico II", PhD Thesis, 2008.

[11] Siemens, "Simcenter Testlab 18.0," 2018.

[12] Siemens, "Modal Analysis," in LMS Test.Lab Manual, pp. Section 1.3.3, Polymax pg. 30 - Section 6.2, MAC, MPC e MPD pg. 228 - Section 8.20, The Multi-Run Modal Analysis pg. 464.

[13] B. D. Allemang, "A correlation coefficient for modal vector analysis," in 1st international modal analysis conference, Orlando, 1982.

[14] J. S. Bendat and A. G. Piersol, "Engineering applications of correlation and spectral analysis," New York, Wiley-Interscience, 1980.

[15] M. R. Gallipoli, M. Mucciarelli and M. Vona, "Empirical estimate of fundamental frequencies and damping for Italian buildings," Earthquake Engineering and Structural Dynamics, vol. 8, no. 38, pp. 973-988, 2009.

[16] Midas IT, "Midas Gen v 1.1," Midasoft Inc., 2019.

[17] Ministero delle Infrastrutture e dei Trasporti, "Circolare n. 617," in Istruzioni per l'applicazione delle "Nuove noerme techniche per le costruzioni" di cui al decreto ministeriale 14 gennaio 2008 (GI n. 47 del 26-2-2009, Suppl. Ordinario n. 27), Roma, Gazzetta Ufficiale, 2009, p. 447.

[18] R. Bricker and C. E. Ventura, "Introduction to Operational Modal Analysis," Wiley Online Library, 2015.

[19] K. V. Yuen and L. S. Katafygiotis, "Bayesian time-domain approach for modal updating using ambient data," Probabilistic Engineering Mechanics, vol. 3, no. 16, pp. 219-231, 2001.

[20] N. Møller, H. Herlufsen and S. Gade, "Stochastic Subspace Identification Techniques in Operational Modal Analysis," in Proc. 1st Int. Operational Modal Analysis Conference, Copenhagen, Denmark, 2005. 